Marquette University

e-Publications@Marquette

Psychology Faculty Research and Publications

Psychology, Department of

6-9-2015

Examination of a Parent-Assisted, FriendshipBuilding Program for Adolescents With ADHD

Denise M. Gardner

Marquette University, denise.gardner@marquette.edu

Alyson C. Gerdes

Marquette University, alyson.gerdes@marquette.edu

Kelsey Ann Weinberger

Marquette University, kelsey.weinberger@marquette.edu

Accepted version. Journal of Attention Disorders (June 9, 2015). DOI. (C) 2015 SAGE Publications. Used with permission. 


\title{
Examination of a Parent-Assisted, Friendship-Building Program for Adolescents with ADHD
}

\author{
Denise M. Gardner \\ Psychology Department, Marquette University \\ Milwaukee, WI \\ Alyson C. Gerdes \\ Psychology Department, Marquette University \\ Milwaukee, WI \\ Kelsey Weinberger \\ Psychology Department, Marquette University \\ Milwaukee, WI
}

\begin{abstract}
Objective: Youth with ADHD experience significant impairment in peer functioning. Based on recommendations from the literature, the current pilot study examined the effectiveness of a parent-assisted, friendship-building program at establishing mutual friendships and improving peer relationships in adolescents with ADHD. Method: Participants included 20 adolescents with
\end{abstract}


NOT THE PUBLISHED VERSION; this is the author's final, peer-reviewed manuscript. The published version may be accessed by following the link in the citation at the bottom of the page.

ADHD (ages 11-16 years) and their parent(s). Families completed the Program for the Evaluation and Enrichment of Relational Skills (PEERS). Measures of friendship quality, social knowledge, social self-efficacy, gettogethers, and peer conflict were completed at baseline and post-treatment. At post-treatment, participants also reported on the initiation of a new friendship. Results: Baseline to post-treatment differences were examined using paired-samples $t$ tests. The majority of participants reported the initiation of a new friendship at post-treatment. Adolescents also demonstrated significantly improved social knowledge and increased gettogethers. Effect sizes were large. Conclusion: Following participation in PEERS, adolescents improved in several peer functioning domains and many initiated new friendships.

Keywords ADHD, adolescence, friendship, treatment

ADHD is a common childhood disorder that often leads to impaired functioning in multiple domains, including peer relationships (American Psychiatric Association [APA], 2013). Specifically, youth with ADHD tend to have fewer friends, lower quality friendships, and experience greater peer victimization than typically developing peers (Hoza, 2007). While previous research has demonstrated that many children with ADHD continue to meet diagnostic criteria and experience impaired peer relationships in adolescence, the majority of treatment research continues to focus on school-aged populations (Hurtig et al., 2007). Given that adolescence is typically the time when teens begin to take more responsibility for the development and maintenance of their peer relationships, adolescence may be a crucial time to assess peer functioning and implement peer interventions for teens with ADHD (Mikami, 2010).

Previous studies have highlighted the importance of mutual friendships and their impact on peer functioning and social development (Bollmer, Milich, Harris, \& Maras, 2005; Frankel \& Whitham, 2011; Mikami, 2010; Newcomb \& Bagwell, 1995). For example, Bollmer and colleagues (2005) found that the presence of at least one mutual friendship during childhood appeared to compensate for the consequences of peer rejection and victimization and lead to better adjustment and acquisition of social competence. Research by Becker, Fite, Luebbe, Stoppelbein, and Greening (2013) indicated that perceived friendship intimacy exchange (e.g., self-disclosure of emotions) functioned as a buffer against later social problems (e.g., peer rejection) for boys and girls. Furthermore, close friendships allow

Journal of Attention Disorders, (June 9, 2015). DOI. This article is @ SAGE Publications and permission has been granted for this version to appear in e-Publications@Marquette. SAGE Publications does not grant permission for this article to be further copied/distributed or hosted elsewhere without the express permission from SAGE Publications. 
children to learn conflict resolution strategies and social problemsolving skills (Mikami, 2010), which may provide an advantage during peer interactions in adolescence.

\section{Primary Skills Deficits in Youth With ADHD}

Behavioral and cognitive characteristics shared by youth with ADHD, such as aggression and poor problem-solving skills, may contribute to their experience of negative peer relationships. The primary skills deficits experienced by youth with ADHD can be categorized into two broad domains: disruptive/inappropriate social behaviors and sociocognitive/social problem-solving deficits.

Youth with ADHD are more likely to engage in inappropriate behaviors (e.g., impulsivity, intrusiveness, and hostility) and less likely to engage in appropriate social skills (e.g., sharing, cooperation, and turn-taking) than their typically developing peers (Mrug, Hoza, \& Gerdes, 2001; Wehmeier, Schacht, \& Barkley, 2010). These negative behaviors are more likely to occur in unstructured and unsupervised situations (e.g., play) and typically lead to impaired peer relationships (Cordier, Bundy, Hocking, \& Einfeld, 2010; Hodgens, Cole, \& Boldizar, 2000). One area of impairment for youth with ADHD is peer group entry (Ronk, Hund, \& Landau, 2011). For example, children with ADHD may use more attention-getting strategies and talk significantly more about themselves than children without ADHD (Ronk et al., 2011), which may be perceived as socially inappropriate by peers.

Disruptive social behaviors also may reflect a lack of appropriate social knowledge and social competence in youth with ADHD. Children acquire appropriate social knowledge and skills through observational learning and attention to social feedback, a skill which is commonly impaired in children with ADHD (Bacchini, Affuso, \& Trotta, 2008; Hoza, 2007; McQuade \& Hoza, 2008). In fact, many children with ADHD tend to overestimate their social competence, in comparison with parent and teacher reports of competence (Bagwell, Molina, Pelham, \& Hoza, 2001; Heiman, 2005; Hoza et al., 2004, Hoza, Pelham, Dobbs, Owens, \& Pillow, 2002; Ohan \& Johnston, 2011). This phenomenon is known as a positive illusory bias (PIB), which has been defined as a child's overestimation of his or her social competence in relation to his or her actual social competence (Ohan \& Johnston, 
2011). Researchers have hypothesized that the PIB may function as a protective mechanism against feelings of inadequacy, a hypothesis that has been supported by research (Diener \& Milich, 1997; Hoza et al., 2002; Hoza, Waschbusch, Pelham, Molina, \& Milich, 2000). Youth with ADHD tend to demonstrate inadequate social problem-solving skills (e.g., difficulty generating appropriate responses to social scenarios, poor social comprehension; King et al., 2009; Sibley, Evans, \& Serpell, 2010). Barkley (2006) hypothesized that poor inhibitory control, related to frontal lobe impairment, may contribute to difficulty in inhibiting one's own responses long enough to consider and understand another child's perspective. Impairment in age-appropriate social skills may inhibit ability to develop friendships and contribute to experience of negative peer relationships.

\section{Negative Peer Relationships in Youth With ADHD}

Previous research has demonstrated that approximately $82 \%$ of children with ADHD experience negative peer relationships (Hoza, Mrug, et al., 2005). Negative peer relationships are often well established by age 7 , are almost immediately evident in new social situations, and are difficult to overcome (Hoza, 2007; Hoza et al., 2005). Furthermore, negative peer relationships and negative reputations often continue into adolescence and remain a significant source of impairment, even when adolescents no longer meet diagnostic criteria for ADHD (Bagwell et al., 2001; Klein \& Mannuzza, 1991; Mrug et al., 2012; Sibley et al., 2010). Due to the swiftness with which youth with ADHD develop enduring, negative social reputations, changing peer group perceptions may be difficult. Negative peer relationships may be defined in a variety of ways, including absence of mutual friendships/poor-quality friendships, peer stigmatization, and peer neglect/rejection.

According to the literature, between $56 \%$ and $76 \%$ of children with ADHD have no mutual friendships (Hoza, Mrug, et al., 2005). Furthermore, the friendships of children with ADHD tend to be characterized by fewer positive features, more negative features, and less stability than those of typically developing peers (Blachman \& Hinshaw, 2002; Hoza et al., 2005; Normand, et al., 2011). Previous research has also demonstrated that children hold more negative 
attributions and fewer positive attributions for peers with ADHD than for peers with asthma or depression (Walker, Coleman, Lee, Squire, \& Friesen, 2008). Youth with ADHD also tend to experience greater peer neglect (i.e., being ignored and socially isolated) and active rejection than typically developing children (Hoza, 2007; Hoza et al., 2005; Pelham \& Bender, 1982). The experience of peer neglect and rejection in childhood and adolescence has been associated with future negative outcomes, such as internalizing symptoms, school avoidance and dropout, substance abuse, and delinquency (Buhs, Ladd, \& Herald, 2001; Mrug et al., 2012). While peer relationship difficulties in youth with ADHD represent a significant area of concern, historically, few interventions for youth with ADHD have focused solely on improvement of peer functioning and development of dyadic friendships (Frankel, Myatt, Cantwell, \& Feinberg, 1997; Hoza, 2007; MTA Cooperative Group, 1999).

\section{Peer Functioning Interventions for ADHD}

\section{Social Skills Training and Friendship-Building Programs}

The limited number of studies examining peer functioning interventions for youth with ADHD can be classified as examinations of social skills training programs, with the exception of the Children's Friendship Training (CFT) program. The primary goal of social skills training programs is to teach appropriate social skills and behaviors to children with peer functioning difficulties (Mrug et al., 2001). Social skills interventions have demonstrated effectiveness in $70 \%$ to $80 \%$ of nonclinical samples; however, between $40 \%$ and $50 \%$ of children did not demonstrate improvement in peer nomination measures (see Hoza, Gerdes, et al., 2005, for reviews). In addition, a meta-analysis examining the results of social skills interventions found that, overall, participants demonstrated only an $8 \%$ improvement over a notreatment condition (see Hoza et al., 2005, for reviews). As a result of unsatisfactory outcomes, researchers have examined the effectiveness of modified social skills programs in the context of the Summer Treatment Program (STP) for youth with ADHD (Antshel \& Remer, 2003; Hoza, Mrug, Pelham, Greiner, \& Gnagy, 2003; Mrug et al., 2001; Pfiffner \& McBurnett, 1997).

Journal of Attention Disorders, (June 9, 2015). DOI. This article is (C) SAGE Publications and permission has been granted for this version to appear in e-Publications@Marquette. SAGE Publications does not grant permission for this article to be further copied/distributed or hosted elsewhere without the express permission from SAGE Publications. 
STP. The STP is an intensive 8-week treatment program for youth with ADHD. The primarily child-focused program targets behavior modification training in classroom, recreational, and peer contexts (Pelham, Fabiano, Gnagy, Greiner, \& Hoza, 1996). Brief group-based social skills training sessions are provided daily. Children receive positive reinforcement of appropriate social skills from counselors and other group members throughout the program day (Pelham, Fabiano, Gnagy, Greiner, \& Hoza, 1996). Overall, results of the STP have demonstrated that, despite improvements in behavioral functioning in both recreational and classroom contexts, participants did not demonstrate long-term improvements in peer functioning, as measured by peer nominations (Hoza, Gerdes, et al., 2005).

In the context of the STP, researchers have examined the effectiveness of modified social skills programs, including a parent component and a "buddy system" intervention. The goal of the parent component study was to examine the impact of parent involvement on the generalization of social skills outside of the treatment setting (Pfiffner \& McBurnett, 1997). The authors compared the treatment effects of a traditional social skills group with a social skills group with a parent component. Parents in the modified social skills group attended weekly sessions and were instructed to prompt their child to use his or her social skills throughout the week. Results of the study indicated that children in both groups demonstrated improved social interaction skills; however, children in the social skills only group demonstrated less generalization to other settings and were less likely to maintain treatment gains than children in the parent group (Pfiffner \& McBurnett, 1997). The goal of the "buddy system" intervention was to target dyadic friendship formation. For the study, participating children were paired with another child from the program based on friendship preferences. Children participated in a variety of shared activities with their buddies, and parents were asked to arrange gettogethers with the two children outside of the program environment. Overall, children whose parents consistently followed through with the "buddy system" intervention demonstrated a greater overall improvement at the end of the program (Hoza et al., 2003; Mrug et al., 2001). This provides support for the importance of get-togethers and parental involvement in psychosocial interventions.

Journal of Attention Disorders, (June 9, 2015). DOI. This article is (C) SAGE Publications and permission has been granted for this version to appear in e-Publications@Marquette. SAGE Publications does not grant permission for this article to be further copied/distributed or hosted elsewhere without the express permission from SAGE Publications. 
CFT. The CFT program (Frankel \& Myatt, 2003) is a 12-week groupbased intervention designed for school-aged children with peer functioning difficulties. The CFT program consists of 90-min structured sessions for both children and their parents (Frankel \& Myatt, 2003). Parent and child sessions are led by a trained professional or a paraprofessional who is assisted by two behavior "coaches" (typically undergraduate research assistants). Parent and child groups are held concurrently and include both didactic and behavioral rehearsal components (Frankel \& Myatt, 2003). Throughout the program, children are taught a variety of socialization skills, including conversational skills, peer group entry, good sportsmanship, appropriate responses to teasing, and conflict resolution (Frankel \& Myatt, 2003). Parents and children are given weekly homework assignments (e.g., hosting get-togethers) to assist with the acquisition of new skills learned during CFT sessions. A study examining the effectiveness of the CFT program for children with ADHD demonstrated that $82.4 \%$ of children in the treatment group demonstrated significantly better outcomes on all treatment variables at posttreatment compared with the average waitlist control (WLC) child (Frankel et al., 1997). Furthermore, studies have demonstrated that treatment gains were maintained 3 months following the intervention (Frankel \& Myatt, 2007; Frankel et al., 1997).

The CFT program addresses several limitations of other peer functioning programs (e.g., social skills training within the STP) by providing a stand-alone intervention for improvement of peer relationships and including a parent component to promote generalization of skills; however, the CFT program focuses solely on school-aged children, does not assess dyadic friendship building at post-treatment, and has not been replicated by another research group.

Program for the Evaluation and Enrichment of Relational Skills (PEERS). Friendship-building programs, such as PEERS, address all of the limitations of previous interventions by providing a long-term, stand-alone program, including a parental component, and focusing on dyadic friendship building. The primary goal of PEERS-originally developed for the autism spectrum disorder (ASD) population-is to assist youth in developing social competence and dyadic friendships (Laugeson, Frankel, Mogil, \& Dillon, 2009). PEERS, adapted from CFT, 
is an intensive 14-week intervention designed to assist adolescents in learning appropriate social skills, expanding their peer network, and managing peer conflict (Laugeson \& Frankel, 2010). PEERS is structured similarly to the CFT program with didactic and behavioral rehearsal components, as well as structured out-of-group homework assignments. The primary outcome of PEERS is for adolescents to develop at least one dyadic friendship (Laugeson et al., 2009). Results of a study conducted by Laugeson and colleagues (2009) demonstrated that adolescents with ASD exhibited improvement in social knowledge, frequency of hosted get-togethers, friendship quality, and overall social skills compared with adolescents in the WLC group. In addition, treatment gains generalized outside of the program and were maintained 3 months post-treatment (Laugeson et al., 2009). The PEERS intervention for youth with ASD has been replicated by other researchers (Schohl et al., 2014). Favorable outcomes of PEERS for adolescents with ASD provide promising evidence for its potential effectiveness with other adolescent populations, such as teens with ADHD. Currently, there are no published studies examining the effectiveness of PEERS for adolescents with ADHD.

\section{Current Study}

The goal of the current pilot study was to examine the effectiveness of PEERS at establishing mutual friendships and improving current peer relationships in a population that has yet to be examined-adolescents with ADHD. The current study addresses all recommendations for effective peer functioning interventions for youth with ADHD (e.g., stand-alone program, parental involvement, and focus on dyadic peer relationships). Following PEERS, it was predicted:

1. Hypothesis 1: Parents and adolescents would report the initiation of at least one mutual friendship.

2. Hypothesis 2: Adolescents would report significantly higher quality of existing friendships relative to baseline.

3. Hypothesis 3: Adolescents would demonstrate significantly improved social knowledge relative to baseline.

4. Hypothesis 4: Adolescents would report significantly higher social self-efficacy relative to baseline.

5. Hypothesis 5: Parents and adolescents would report increased frequency of hosted get-togethers (Part 1) and significantly

Journal of Attention Disorders, (June 9, 2015). DOI. This article is C SAGE Publications and permission has been granted for this version to appear in e-Publications@Marquette. SAGE Publications does not grant permission for this article to be further copied/distributed or hosted elsewhere without the express permission from SAGE Publications. 
lower levels of peer conflict during get-togethers relative to baseline (Part 2).

\section{Method}

\section{Recruitment}

Four recruitment methods were utilized. Eligible families who had previously completed a parent training intervention through a university-based clinic received a letter explaining the study, which was followed by a telephone call from one of the researchers. In addition, several mental health professionals in the same community were asked to distribute recruitment fliers to eligible families. In addition, guidance counselors and special education teachers at various local high schools were contacted and asked to distribute recruitment fliers to eligible families. Finally, upon completion of the group, participating families were given recruitment fliers and were asked to distribute the fliers to other families who may be interested in participating. Twenty-five families were initially recruited for the study; however, five families dropped out of the study prior to completing the treatment and are not included in the analyses. Reasons for dropout included teen loss of interest in participating $(n=3)$, parent loss of interest in participating $(n=1)$, and family chose to participate in an alternative peer intervention program $(n=1)$. Differences in initial impairment were examined for the two groups, and no statistically significant differences emerged (i.e., adolescents who completed treatment vs. those who dropped out did not differ with regard to parent-reported ADHD symptoms or degree of functional impairment in peer relationships at the time of assessment).

\section{Participants}

Participants included 20 adolescents, aged 11 to 16 years, and their parent(s) who met the inclusion criteria. First, participating adolescents had to definitively state interest in participating in the group. Adolescent interest and motivation for participation also were assessed through a structured interview during the pre-assessment. Second, adolescents and parents had to express willingness to attend all PEERS sessions, with a maximum of two absences allowed. Third, 
adolescents and parents had to be able to speak English and be without any cognitive or developmental delays that would affect reading comprehension and understanding of treatment material. Finally, adolescents had to receive a previous diagnosis of ADHD and exhibit current functional impairment in peer relationships, which was confirmed during the parent interview and on the peer functioning scale of the ADHD-FX scale, which assesses functional impairment in peer relationships (e.g., "is ignored, rejected and/or teased by peers"; Haack, Gerdes, \& Lawton, 2014).

Interested families completed a telephone screening to ensure that adolescents met the criteria for inclusion in PEERS. Eligible families scheduled a 2-hr intake appointment at a university-based clinic. Once the intake had been scheduled, pre-assessment questionnaire packets used to confirm current functional impairment in peer relationships were sent to families to complete and return at their intake appointment.

Descriptive statistics for demographic characteristics are displayed in Table 1 . Adolescents were predominantly male (70\%) and Caucasian (65\%) with a mean age of 12.4 years. The majority of adolescents were between 11 and 13 years of age, with the exception of one teen who was 16 years old. Participating parents were primarily mothers (80\%) who were married (78.9\%) and had completed at least a bachelor's degree (55.5\%). 
Table I. Demographic Characteristics $(N=20)$.

\begin{tabular}{lc}
\hline Adolescent demographics & \\
Age $(M+S D)$ & $12.4+1.31$ \\
Gender $(n, \%)$ & $14(70)$ \\
Boys & $6(30)$ \\
Girls & $13(65)$ \\
Ethnicity $(n, \%)$ & $3(15)$ \\
$\quad$ Caucasian & $3(15)$ \\
$\quad$ Latino/Hispanic & $1(5)$ \\
African American & \\
Asian & \\
Parent demographics & $15(78.9)$ \\
Marital status $(n, \%)^{\mathrm{a}}$ & $3(15.8)$ \\
$\quad$ Married & $1(5.3)$ \\
Unmarried & \\
Divorced & $2(11.2)$ \\
Education (n, \%) & \\
Partial high school/graduated high & $6(33.3)$ \\
school/GED & $4(22.2)$ \\
Partial college/training & $6(33.3)$ \\
$\quad$ Standard college degree & \\
Graduate/professional training or degree & \\
\hline
\end{tabular}

${ }^{2}$ Missing values.

\section{Procedure}

Pre-assessment. At the intake session, informed parental consent and permission, as well as adolescent assent, were obtained. Following the consent procedures, parents and adolescents completed the remainder of the intake procedures separately. Parents completed an unstructured interview focused on the adolescents' current peer functioning and other relevant psychosocial information. Parents also completed measures about themselves and their adolescent's peer functioning and overall behavior. Adolescents completed a structured interview focused on interest in PEERS and current peer functioning, as well as completed several self-report measures. 
PEERS intervention. Adolescents and their parent(s) attended 14 weekly 90 -min sessions of PEERS. Parent and adolescent sessions were led by trained Master's level graduate students, under the supervision of a licensed psychologist and a certified PEERS provider. Adolescent group leaders were assisted by two undergraduate "coaches." Sessions were implemented according to the manualized treatment protocol as described above. Throughout the course of the intervention, adolescents were taught a variety of skills, including initiating/maintaining conversations, using electronic communication, responding to peer teasing, using appropriate humor, and group entry/exit skills. Early sessions introduced foundational skills (e.g., initiating conversations, finding common interests) and gradually progressed to more advanced skills (e.g., hosting a get-together, changing a negative reputation). Adolescents were assigned weekly homework, and parents were encouraged to discuss homework completion with teens and supervise homework as appropriate (e.g., get-togethers). Examples of homework assignments included phone calls to group members/out-of-group members, hosting get-togethers, and practicing peer group entry. Weekly fidelity checks were conducted to ensure strict adherence to the treatment outline in the PEERS manual (Laugeson \& Frankel, 2010).

\section{Adolescent Outcome Measures}

Question about initiation of a new mutual friendship. Adolescents responded to a question indicating the initiation of a new mutual friendship ("Have you initiated a mutual friendship since beginning PEERS? If so, please provide his/her first name and last initial.").

Friendship Qualities Scale (FQS). The FQS (Bukowski, Hoza, \& Boivin, 1994) is a 23-item adolescent-report measure designed to assess five domains of friendship quality, including companionship, closeness, help, security, and conflict. Respondents are asked to identify their best friend and to keep him or her in mind while answering the yes/no questions (e.g., "My friend and I spend all of our free time together.") The FQS yields a total score ranging from 0 to 115 , with higher scores indicating better quality friendships. According to Bukowski and colleagues (1994), the FQS demonstrates good internal consistency for all subscales, ranging from .71 to .86. For the 
NOT THE PUBLISHED VERSION; this is the author's final, peer-reviewed manuscript. The published version may be accessed by following the link in the citation at the bottom of the page.

current study, the internal consistency for the FQS was .84 (pretreatment) and .93 (post-treatment).

Test of Adolescent Social Skills Knowledge (TASSK). The TASSK is a 26-item adolescent-report measure designed to assess adolescents' knowledge of specific social skills taught during PEERS (Laugeson \& Frankel, 2006). Adolescents are presented with sentence stems and are required to choose between one of two possible answers. The total score on the TASSK ranges from 0 to 26, with higher scores indicating greater social knowledge. Laugeson and colleagues (2009) reported that the internal consistency on the TASSK is moderately good (a $=.56)$. For the current study, the internal consistency for the TASSK was .31 (pre-treatment) and .77 (post-treatment). It is likely that poor social knowledge at pre-treatment contributed to less consistent responding among teens, leading to low internal consistency.

Self-Perception Profile for Children (SPPC). The SPPC is a 36-item child-report measure utilized with children 8 to 13 years of age that assesses five domains of self-concept, including academic competence, social acceptance, athletic competence, physical appearance, and behavioral conduct; the SPPC also contains a measure of global selfworth (Harter, 1985). The current study only examines the Social Acceptance scale. Each item includes pairs of statements that describe perspectives on particular aspects of self-evaluation (e.g., "Some kids wish their body was different, but other kids like their body the way it is."). Respondents are required to choose which statement best describes them and then to rate how well the statement describes them on a 4-point Likert-type scale ranging from sort of true to really true. The mean scores are then computed, with higher scores indicating more positive self-perceptions. The scales of the SPPC demonstrate good internal consistency, with Cronbach's alphas ranging from .80 to .90 (Harter, 1985). For the current study, the internal consistency for the SPPC was .79 (pre-treatment) and .87 (post-treatment).

Self-Perception Profile for Adolescents (SPPA). The SPPA is a 45item adolescent-report measure utilized with adolescents 14 to 18 years of age that assesses eight domains of self-concept, including academic competence, athletic competence, social acceptance, 
physical appearance, behavioral conduct, close friendship, romantic appeal, and job competence; the SPPA also contains a measure of global self-worth (Harter, 1988). The current study examines the Social Acceptance scale. Scores on the SPPA are computed identically to those on the SPPC. According to Harter (1988), the internal consistency of the SPPA ranges from .74 to .93. For the current study, the internal consistency for the SPPA was .82 (pre-treatment) and .81 (post-treatment).

Quality of Socialization Questionnaire-Revised (QSQ-R). The QSQ-R (adapted from Frankel \& Mintz, 2011) is a 12-item self-report measure adapted from the Quality of Play Questionnaire. The QSQ-R is designed to assess teens' frequency of hosted and invited gettogethers over the past month, as well as peer conflict during gettogethers. Adolescents are asked to identify the friend who hosted each get-together, as well as use a 4-point Likert-type scale from 0 (not true at all) to 3 (very much true) to rate their own peer conflict during the get-togethers. According to Frankel and colleagues, the Conflict scale on the QSQ-R has demonstrated good internal consistency ( $\mathrm{a}=.87$ ) and good convergent validity with the Problem Behaviors scale on the Social Skills Rating Scale $(\rho=.35, p<.05)$. For the current study, the internal consistency for the QSQ-R teen report was .70 (pre-treatment) and .81 (post-treatment).

\section{Parent Outcome Measures}

Question about initiation of a new mutual friendship. Parents responded to a question indicating the initiation of a new mutual friendship ("Has your adolescent initiated a mutual friendship since beginning PEERS? If so, please provide his/her first name and last initial.").

QSQ-R. The parent version QSQ-R (adapted from Frankel et al., 2010) is structured nearly identically to the adolescent version. Parents are asked to identify the friend who hosted each get-together, as well as use a 4-point Likert-type scale from 0 (not true at all) to 3 (very much true) to rate their adolescent's conflict with peers during the get- 
togethers. For the current study, the internal consistency of the QSQ-R parent report was .82 (pre-treatment) and .47 (post-treatment).

\section{Results}

\section{Data Analytic Plan}

Hypothesis 1 was examined by calculating the percentage of parents and adolescents who identified the initiation of a mutual friendship at post-treatment. Hypotheses 2, 3, 4, and 5 were examined using a series of paired-samples $t$ tests. Due to the pilot nature of the study, effect sizes (as measured by $\eta^{2}$ ) were also examined. Results for all paired-samples $t$ tests are presented in Table 2.

\begin{tabular}{|c|c|c|c|c|}
\hline & $\begin{array}{l}\text { Pre-treatment } \\
\text { ( } M \text {, SD, range) }\end{array}$ & $\begin{array}{l}\text { Post-treatment } \\
\text { (M, SD, range) }\end{array}$ & $t$ & $\eta^{2}$ \\
\hline \multicolumn{5}{|l|}{ Adolescem measures } \\
\hline FQS & $\begin{array}{c}89.25(11.53) \\
68.114\end{array}$ & $\begin{array}{c}89.95(18.28) \\
31.115\end{array}$ & -0.18 & .002 \\
\hline TASSK & $\begin{array}{c}11.45(2.65) \\
6.17\end{array}$ & $\begin{array}{c}20.75(3.68) \\
13.26\end{array}$ & $-12.50 \mathrm{~m}$ & 89 \\
\hline \multicolumn{5}{|l|}{ SPPCIA } \\
\hline Social acceptance score & $\begin{array}{c}2.31(0.77) \\
1.4 .4\end{array}$ & $\begin{array}{c}2.43(0.86) \\
1.4\end{array}$ & -1.14 & .06 \\
\hline \multicolumn{5}{|l|}{$Q S Q \cdot R$} \\
\hline Hosted get-togethers & $\begin{array}{c}0.90(1.55) \\
0.5\end{array}$ & $\begin{array}{c}6.10(7.23) \\
0.29\end{array}$ & $-3.38=$ & .38 \\
\hline Peer conflict score & $\begin{array}{c}5.50(4.99) \\
1.14\end{array}$ & $\begin{array}{c}3.00(3.59) \\
0.11\end{array}$ & 1.05 & .05 \\
\hline \multicolumn{5}{|l|}{ Parent measures } \\
\hline \multicolumn{5}{|l|}{ QSQR $R$} \\
\hline Hosted get-togethers & $\begin{array}{c}1.12(1.69) \\
0.6\end{array}$ & $\begin{array}{c}2.82(1.33) \\
0.6\end{array}$ & $-3.28^{*}$ & .40 \\
\hline Peer conflict score & $\begin{array}{c}4.80(3.58) \\
0-10\end{array}$ & $\begin{array}{c}3.60(2.07) \\
0-7\end{array}$ & 1.12 & .12 \\
\hline
\end{tabular}

Note. $01=$ amall effect, $06=$ modernte effect, $14=$ turge effect (Cohen, 1988), FQS = Friendship Qualices Sole, TASSK = Test of Adolescent Social Shills Knowlodge: SPPCIA = Selt.Perception Profile for Children/Adoletsents: $Q S Q-R=$ Quality of Socialization Quetrionnaire-Revised. $7 p<.05,-p<.01, \cdots p<.001$

\section{Primary Analyses}

Consistent with our first hypothesis that parents and adolescents would report the initiation of at least one mutual friend, $78.9 \%$ of parents and $68.4 \%$ of adolescents reported the initiation of a mutual friendship at post-treatment $(n=19)$. Our third prediction related to significantly improved social knowledge also was supported; a statistically significant increase in social knowledge, as measured by the TASSK, from baseline to post-treatment emerged, $t(19)=-12.50, p<.001$. The $\eta^{2}$ statistic $(.89)$ indicated a large effect 
size. Consistent with the first part of our fifth hypothesis related to increased frequency of hosted get-together, a significant increase in the frequency of hosted get-togethers reported by parents, $t(16)=$ $-3.28, p<.05$, and adolescents, $t(19)=-3.38, p<.01$, was found. The $\eta^{2}$ statistics (.40 and .38, respectively) indicated large effect sizes. Furthermore, at the end of the treatment, $94.4 \%$ of parents and $90 \%$ of adolescents reported that the adolescent had hosted at least one get-together over the past month.

While the observed changes in post-treatment friendship quality as measured by the FQS (Hypothesis 2), adolescent social self-efficacy as measured by the SPPC/SPPA (Hypotheses 4), and parent-reported peer conflict during get-togethers as measured by the QSQ-R (Part 2 of Hypothesis 5) were in the expected direction, results did not reach statistical significance. Importantly, a moderate effect size emerged for adolescent social self-efficacy $\left(\eta^{2}=.06\right)$ and a large effect size emerged for parent-reported peer conflict during get-togethers $\left(\eta^{2}\right.$ $=.12$ ). Unfortunately, the peer conflict score on the QSQ-R is computed only if the adolescent reported hosting a get-together in the past month; thus, analyses were conducted on an even smaller sample.

\section{Discussion}

The current study examined the effectiveness of PEERS, a parent-assisted, friendship-building program, at establishing mutual friendships and improving peer relationships in adolescents with ADHD. The primary purpose was to collect pilot data with a new population to establish effect sizes for a future WLC study with a larger sample size. Overall, results were in the expected direction with several analyses reaching statistical significance. Moderate to large effect sizes were observed for many outcome measures.

One of the most important findings that emerged from the current study was the large number of adolescents and parents who reported the initiation of a new, mutual friendship at post-treatment. While it is important to consider the impact of PIB on adolescent report of friendship initiation, parent report (which was completed separately by adolescents) may serve as confirmation. As noted earlier, researchers have highlighted the importance of focusing on dyadic 
friendship formation rather than peer group acceptance as an outcome measure for peer interventions (Hoza, 2007; Mikami, 2010; Normand et al., 2011). While results have been mixed, researchers argue that the presence of at least one mutual friendship may function as a protective factor against the consequences of negative peer interactions (Bollmer et al., 2005; Cardoos \& Hinshaw, 2011) and allow youth to build social competence within a supportive relationship (Mikami, 2010; Nelson \& Aboud, 1985). Thus, the establishment of a new mutual friendship following participation in PEERS provides initial support for the effectiveness of the program for adolescents with ADHD.

Notably, there was also a statistically significant improvement in adolescent social knowledge at post-treatment relative to baseline. These findings are similar to those reported by Laugeson and colleagues (2009) who found that adolescents with ASD demonstrated improved social knowledge at post-treatment. In addition to the significance of improvement, the effect size was large and comparable with those reported by Frankel and colleagues (1997) for school-aged children with ADHD participating in the CFT program. Improvement in social knowledge is likely an initial step in improved social functioning. For example, researchers have consistently illustrated the importance of appropriate social knowledge in contributing to successful social interactions and positive peer relationships (Hoza et al., 2000; Ronk et al., 2011). Further assessment is necessary to determine if improved social knowledge translates into improved social functioning in the real world.

In addition, parents and adolescents reported a significant increase in the frequency of hosted get-togethers at post-treatment relative to baseline. Again, these findings parallel those reported by Laugeson and colleagues (2009) with their sample of adolescents with ASD. Furthermore, the observed effect size for this change was large. While hosted get-togethers are a part of assigned homework, many families require significant guidance and problem solving with group leaders to complete these homework assignments. As such, significant increases in hosted get-togethers are not simply a function of homework expectations but are reflective of the training and guidance provided by the intervention. Previous research has demonstrated that school-aged children whose parents consistently organized get- 
togethers demonstrated a greater overall improvement than children whose parents were not consistent in planning get-togethers (Hoza et al., 2003; Mrug et al., 2001). This research, along with the current finding, provides support for the importance of get-togethers as a component of effective peer interventions for youth.

Contrary to our hypothesis, adolescents did not report statistically significant higher quality of existing friendships at posttreatment relative to baseline. Examination of pre-treatment means indicated that, on average, adolescents reported moderately highquality friendships at baseline, suggesting that there was less opportunity for improvement at post-treatment. In addition, this finding may illustrate that improvement in friendship quality may require additional time to develop beyond the final treatment session. To investigate this hypothesis, it would be necessary to assess treatment outcomes at a follow-up session 3 to 6 months posttreatment.

It is also important to consider the potential impact of the PIB in the baseline estimation of friendship quality. As discussed earlier, youth with ADHD tend to overestimate their social competence relative to observer ratings of their actual social competence (Bagwell et al., 2001; Heiman, 2005; Hoza et al., 2004, Hoza et al., 2002; Ohan \& Johnston, 2011). Researchers have hypothesized that PIB may function as a protective mechanism against feelings of inadequacy (Diener \& Milich, 1997; Hoza et al., 2000) or may be the result of inadequate social knowledge and self-monitoring (Hoza et al., 2002). Thus, it is important to consider the accuracy of adolescent-reported friendship quality and may indicate that additional respondents are necessary for future studies.

Interestingly, adolescents also did not report statistically significantly higher social self-efficacy at post-treatment; however, results were in the expected direction, and a moderate effect size emerged. It is possible that results will reach statistical significance with a larger sample size. Previous research has demonstrated that negative social reputations among youth with ADHD may be difficult to change (Hoza, 2007; Hoza, Mrug, et al., 2005). Thus, it is also possible that while teens likely began experiencing some positive social interactions during participation in PEERS, they may also have 
continued to experience negative and unsuccessful interactions, which could have affected their ratings of social self-efficacy.

Finally, parents and adolescents did not report significant decreases in peer conflict during get-togethers at post-treatment. Despite lack of significance, results were in the expected direction, and small (teen report) to large (parent report) effect sizes were observed. As many teens had not hosted get-togethers at baseline, these analyses were conducted with an even smaller sample size. Analyses conducted using a larger sample likely would have resulted in statistically significant decreases in peer conflict at post-treatment.

\section{Limitations}

Although the current study incorporated recommendations from the literature and demonstrated the effectiveness of PEERS as a peer functioning intervention for teens with ADHD, there are several limitations. First, while the purpose of the study was to collect pilot data to establish effect sizes, the sample size was small. This likely had an effect on the significance level of some of the results. A second limitation is the absence of a WLC group, which would allow for comparison of outcomes at post-treatment to establish whether PEERS is more effective than a WLC condition. Although this line of work is worth pursuing, the literature suggests that due to the typical severity of peer functioning difficulties among youth with ADHD, spontaneous remission would not be expected without intervention. A third limitation is related to ADHD subtype diagnosis and comorbidity. While several treatment variables improved over the course of the intervention, the study did not examine differences in effectiveness relative to subtype or comorbid diagnoses; this was due to the small sample size. Research indicates that children with ADHD may exhibit different peer interaction difficulties based on subtype (Cordier et al., 2010; Hodgens et al., 2000) and comorbidity (Wilens et al., 2002). Important comorbidities to consider include anxiety, depression, and ASD. Examination of outcomes relative to subtype and comorbidity would allow for a more comprehensive understanding of the effectiveness of PEERS for the ADHD population. Fourth, outcome measures relied on parent and adolescent report and were not confirmed by a third-party source (e.g., teacher). Future studies 
NOT THE PUBLISHED VERSION; this is the author's final, peer-reviewed manuscript. The published version may be accessed by following the link in the citation at the bottom of the page.

should include additional reporters to provide further confirmation of outcome data.

\section{Clinical Implications and Future Directions}

Despite these limitations, the current findings have several important clinical implications. The current pilot study expands upon the existing clinical interventions for youth with ADHD by examining the effectiveness of PEERS with an ADHD sample. PEERS includes all of the elements recommended by experts, including a focus on dyadic friendship formation, a parental component, and a stand-alone peer functioning intervention. Initial findings suggest that PEERS is an effective clinical intervention for improving dyadic friendship formation, social knowledge, and frequency of hosted get-togethers in teens with ADHD.

Future research should incorporate a WLC group to investigate whether PEERS improves peer functioning in comparison with a WLC condition. Future research should also examine outcomes relative to ADHD subtype and comorbidity. In addition, future research on the effectiveness of PEERS for teens with ADHD should include follow-up sessions at 3 months post-treatment and 6 months post-treatment as a means of assessing maintenance of treatment gains. Follow-up sessions would also allow for assessment of treatment variables that may require additional time to reach significance. Finally, future research should examine whether modification to the current PEERS program could increase effectiveness for youth with ADHD.

As PEERS was created for teens with ASD, there may be specific components of the program that require modification (addition or deletion) to better target youth with ADHD. There are a number of modifications that may be considered for the ADHD population. First, PEERS introduces the concept of "geek" culture, which may be more applicable to teens with ASD. Second, PEERS does not directly address bragging, which is a common concern in the ADHD population. Third, PEERS does not directly address anxiety (as it relates to social interactions), which is commonly comorbid with ADHD. Careful examination of session content and professional consultation would likely facilitate the modification of the program, which could later be pilot tested. 
In summary, results of the current pilot study provide support for the effectiveness of the PEERS intervention for adolescents with ADHD. Furthermore, PEERS addresses limitations of previous peer functioning interventions and responds to researcher recommendations. PEERS provides an additional option for peer functioning interventions with the ADHD population.

Declaration of Conflicting Interests The author(s) declared no potential conflicts of interest with respect to the research, authorship, and/or publication of this article.

Funding The author(s) received no financial support for the research, authorship, and/or publication of this article.

\section{References}

American Psychiatric Association. (2013). Diagnostic and statistical manual of mental disorders (5th ed.). Arlington, VA: American Psychiatric Publishing.

Antshel K. M., Remer R. (2003). Social skills training in children with attention deficit hyperactivity disorder: A randomized-controlled clinical trial. Journal of Clinical Child \& Adolescent Psychology, 32, 153-165.

Bacchini D., Affuso G., Trotta T. (2008). Temperament, ADHD, and peer relations among schoolchildren: The mediating role of school bullying. Aggressive Behavior, 34, 447-459. doi:10.1002/ab.20271,

Bagwell C. L., Molina B. S., Pelham W. E., Hoza B. (2001). Attentiondeficit/hyperactivity disorder and problems in peer relations: Predictions from childhood to adolescence. Journal of the American Academy of Child \& Adolescent Psychiatry, 40, 1285-1292.

Barkley R. A. (2006). Attention-deficit/hyperactivity disorder: A handbook for diagnosis and treatment. New York, NY: Guilford Press.

Becker S. P., Fite P. J., Luebbe A. M., Stoppelbein L., Greening L. (2013). Friendship intimacy exchange buffers the relation between ADHD symptoms and later social problems among children attending an after-school care program. Journal of Psychopathology and Behavioral Assessment, 35, 142-152. doi:10.1007/s10862-012-9334-1

Blachman D. R., Hinshaw S. P. (2002). Patterns of friendship among girls with and without attention-deficit/hyperactivity disorder. Journal of Abnormal Child Psychology, 30, 625-640.

Journal of Attention Disorders, (June 9, 2015). DOI. This article is (C) SAGE Publications and permission has been granted for this version to appear in e-Publications@Marquette. SAGE Publications does not grant permission for this article to be further copied/distributed or hosted elsewhere without the express permission from SAGE Publications. 
NOT THE PUBLISHED VERSION; this is the author's final, peer-reviewed manuscript. The published version may be

accessed by following the link in the citation at the bottom of the page.

Bollmer J. M., Milich R., Harris M. J., Maras M. A. (2005). A friend in need: The role of friendship quality as a protective factor in peer victimization and bullying. Journal of Interpersonal Violence, 20, 701712. doi:10.1177/0886260504272897

Buhs E. S., Ladd G. W., Herald S. L. (2001). Peer exclusion and victimization: Processes that mediate the relation between peer group rejection and children's classroom engagement and achievement. Journal of Educational Psychology, 98, 1-13.

Bukowski W., Hoza B., Boivin M. (1994). Measuring friendship quality during pre- and early adolescence: The development and psychometric properties of the Friendship Qualities Scale. Journal of Social and Personal Relationships, 11, 471-484.

Cardoos S. L., Hinshaw S. P. (2011). Friendship as protection from peer victimization for girls with and without ADHD. Journal of Abnormal Child Psychology, 39, 1035-1045. doi:10.1007/s10802-011-9517-3,

Cohen J. (1988). Statistical power analysis for the behavioral sciences (2nd ed.). Hillsdale, NJ: Lawrence Earlbaum Associates.

Cordier R., Bundy A., Hocking C., Einfeld S. (2010). Comparison of play with children with attention-deficit/hyperactivity disorder by subtypes. Australian Occupational Therapy Journal, 57, 137-145. doi:10.1111/j.1440-1630.2009.00821.x

Diener M. B., Milich R. (1997). Effects of positive feedback on the social interactions of boys with attention deficit hyperactivity disorder: A test of the self-protective hypothesis. Journal of Clinical Child Psychology, 26, 256-265. doi:10.1207/s15374424jccp2603_4

Frankel F., Mintz J. (2011). Maternal reports of play dates of clinic referred and community children. Journal of Child and Family Studies, 20, 623630.

Frankel F., Myatt R. (2003). Children's friendship training. New York, NY: Brunner-Routledge.

Frankel F., Myatt R. (2007). Parent-assisted friendship training for children with autism spectrum disorders: Effects associated with psychotropic medication. Child Psychiatry \& Human Development, 37, 337-346. ,

Frankel F., Myatt R., Cantwell D. P., Feinberg D. T. (1997). Parent-assisted transfer of children's social skills training: Effects on children with and without attention-deficit/hyperactivity disorder. Journal of the American Academy of Child \& Adolescent Psychiatry, 36, 1056-1064. ,

Frankel F., Whitham C. (2011). Parent-assisted group treatment for friendship problems of children with autism spectrum disorders. Brain Research, 1380, 240-245. doi:10.1016/j.brainres.2010.09.047,

Journal of Attention Disorders, (June 9, 2015). DOI. This article is (C) SAGE Publications and permission has been granted for this version to appear in e-Publications@Marquette. SAGE Publications does not grant permission for this article to be further copied/distributed or hosted elsewhere without the express permission from SAGE Publications. 
NOT THE PUBLISHED VERSION; this is the author's final, peer-reviewed manuscript. The published version may be accessed by following the link in the citation at the bottom of the page.

Haack L. M., Gerdes A. C., Lawton K. E. (2014). Understanding and measuring functional impairment in diverse children with ADHD: Development and validation of the ADHD-FX Scale. Journal of Clinical Child \& Adolescent Psychology. Advance online publication.

Harter S. (1985). Manual for the Self-Perception Profile for Children. Unpublished manuscript, Denver, CO.

Harter S. (1988). Manual for the Self-Perception Profile for Adolescents. Unpublished manuscript, Denver, CO.

Heiman T. (2005). An examination of peer relationships of children with and without attention deficit hyperactivity disorder. School Psychology International, 26, 330-339. doi:10.1177/0143034305055977

Hodgens J. B., Cole J., Boldizar J. (2000). Peer-based differences among boys with ADHD. Journal of Clinical Child Psychology, 29, 443-452. doi:10.1207/S15374424JCCP2903_15

Hoza B. (2007). Peer functioning in children with ADHD. Ambulatory Pediatrics, 7, 101-106.

Hoza B., Gerdes A. C., Hinshaw S. P., Arnold L. E., Pelham W. E., Molina B. S., . . . Wigal T. (2004). Self-perceptions of competence in children with ADHD and comparison children. Journal of Consulting and Clinical Psychology, 72, 382-391. doi:10.1037/0022-006X.72.3.382

Hoza B., Gerdes A. C., Mrug S., Hinshaw S. P., Bukowski W. M., Gold J. A., . . . Wigal T. (2005). Peer-assessed outcomes in the multimodal treatment study of children with attention deficit hyperactivity disorder. Journal of Clinical Child \& Adolescent Psychology, 34, 74-86.

Hoza B., Mrug S., Gerdes A. C., Hinshaw S. P., Bukowski W. M., Gold J. A., . . . Arnold L. E. (2005). What aspects of peer relationships are impaired in children with attention-deficit/hyperactivity disorder? Journal of Consulting and Clinical Psychology, 73, 411-423.

Hoza B., Mrug S., Pelham W. E., Greiner A. R., Gnagy E. M. (2003). A friendship intervention for children with attention-deficit/hyperactivity disorder: Preliminary findings. Journal of Attention Disorders, 6, 8798. doi:10.1177/108705470300600301

Hoza B., Pelham W. E., Dobbs J., Owens J. S., Pillow D. R. (2002). Do boys with attention-deficit/hyperactivity disorder have positive illusory selfconcepts? Journal of Abnormal Psychology, 111, 268-278. doi:10.1037/0021-843X.111.2.268

Hoza B., Waschbusch D. A., Pelham W. E., Molina B. S., Milich R. (2000). Attention-deficit/hyperactivity disordered and control boys' response to social success and failure. Child Development, 71, 432-446. ,

Journal of Attention Disorders, (June 9, 2015). DOI. This article is (C) SAGE Publications and permission has been granted for this version to appear in e-Publications@Marquette. SAGE Publications does not grant permission for this article to be further copied/distributed or hosted elsewhere without the express permission from SAGE Publications. 
NOT THE PUBLISHED VERSION; this is the author's final, peer-reviewed manuscript. The published version may be accessed by following the link in the citation at the bottom of the page.

Hurtig T., Ebeling H., Taanila A., Miettunen J., Smalley S. L., McGough J. J., ... Moilanen I. K. (2007). ADHD symptoms and subtypes: Relationship between childhood and adolescent symptoms. Journal of the American Academy of Child \& Adolescent Psychiatry, 46, 16051613.

King S., Waschbusch D. A., Pelham W. E., Frankland B. W., Andrade B. F., Jacques S., Corkum P. V. (2009). Social information processing in elementary-school aged children with ADHD: Medication effects and comparisons with typical children. Journal of Abnormal Child Psychology, 37, 579-589. doi:10.1007/s10802-008-9294-9

Klein R. G., Mannuzza S. (1991). Long-term outcome of hyperactive children: A review. Journal of the American Academy of Child and Adolescent Psychiatry, 30, 383-387.

Laugeson E. A., Frankel F. (2006). Test of Adolescent Social Skills Knowledge. Available from UCLA Parenting and Children's Friendship Program, 300 Medical Plaza, Los Angeles, CA.

Laugeson E. A., Frankel F. (2010). Social skills for teenagers with developmental and autism spectrum disorders: The PEERS treatment manual. New York, NY: Routledge.

Laugeson E. A., Frankel F., Mogil C., Dillon A. R. (2009). Parent-assisted social skills training to improve friendships in teens with autism spectrum disorders. Journal of Autism and Developmental Disorders, 39, 596-606. doi:10.1007/s10803-008-0664-5

McQuade J. D., Hoza B. (2008). Peer problems in attention deficit hyperactivity disorder: Current status and future directions. Developmental Disabilities, 14, 320-324. doi:10.1002/ddrr.35

Mikami A. Y. (2010). The importance of friendship for youth with attentiondeficit/ hyperactivity disorder. Clinical Child and Family Psychology Review, 13, 181-198. doi:10.1007/s10-567-010-0067-y

Mrug S., Hoza B., Gerdes A. C. (2001). Children with attentiondeficit/hyperactivity disorder: Peer relationships and peer-oriented interventions. In Nangle D. W., Erdley C. A. (Eds.), The role of friendship in psychological adjustment (pp. 51-78). San Francisco, CA: Jossey-Bass.

Mrug S., Molina B. S., Hoza B., Gerdes A. C., Hinshaw S. P., Hectman L., Arnold L. E. (2012). Peer rejection and friendships in children with attention-deficit/hyperactivity disorder: Contributions to long-term outcomes. Journal of Abnormal Child Psychology, 40, 1013-1026. doi: $10.1007 / \mathrm{s} 10802-012-9610-2$

MTA Cooperative Group. (1999). A 14-month randomized clinical trial of treatment strategies for attention-deficit/hyperactivity disorder.

Journal of Attention Disorders, (June 9, 2015). DOI. This article is (C) SAGE Publications and permission has been granted for this version to appear in e-Publications@Marquette. SAGE Publications does not grant permission for this article to be further copied/distributed or hosted elsewhere without the express permission from SAGE Publications. 
NOT THE PUBLISHED VERSION; this is the author's final, peer-reviewed manuscript. The published version may be accessed by following the link in the citation at the bottom of the page.

Archives of General Psychiatry, 56, 1073-1086. doi:10.1001/archpsyc.56.12.1073

Nelson J., Aboud F. E. (1985). The resolution of social conflict between friends. Child Development, 56, 1009-1017.

Newcomb A. F., Bagwell C. L. (1995). Children's friendship relations: A meta-analytic review. Psychological Bulletin, 117, 306-347. doi:10.1037/0033-2909.117.2.306

Normand S., Schneider B. H., Lee M. D., Masionneuve M. F., Keuhn S. M., Robaey P. (2011). How do children with ADHD (mis)manage their real-life dyadic friendships? A multi-method investigation. Journal of Abnormal Child Psychology, 39, 293-305. doi:10.1007/s10802-0109450-x

Ohan J. L., Johnston C. (2011). Positive illusions of social competence in girls with and without ADHD. Journal of Abnormal Child Psychology, 39, 527-539. doi:10.1007/s10802-010-9484-0

Pelham W. E., Bender M. E. (1982). Peer relationships in hyperactive children: Description and treatment. Advances in Learning and Behavioral Disabilities, 1, 365-436.

Pelham W. E.Jr., Fabiano G. A., Gnagy E. M., Greiner A. R., Hoza B. (1996). Intensive treatment: A summer treatment program for children with ADHD. In Hibbs E. D., Jensen P. S. (Eds.), Psychosocial treatments for child and adolescent disorders: Empirically-based strategies for clinical practice (pp. 377-410). Washington, DC: American Psychological Association.

Pfiffner L. J., McBurnett K. (1997). Social skills training with parent generalization: Treatment effects for children with attention deficit disorder. Journal of Consulting and Clinical Psychology, 65, 749-757.

Ronk M. J., Hund A. M., Landau S. (2011). Assessment of social competence of boys with attention-deficit/hyperactivity disorder: Problematic peer entry, host responses, and evaluations. Journal of Abnormal Child Psychology, 39, 829-840. doi:10.1007/s10802-011-9497-3

Schohl K. A., Van Hecke A. V., Carson A. M., Dolan B., Karst J., Stevens S. (2014). A replication and extension of the PEERS intervention: Examining effects of social skills and social anxiety in adolescents with autism spectrum disorders. Journal of Autism and Developmental Disorders, 44, 532-545.

Sibley M. H., Evans S. W., Serpell Z. N. (2010). Social cognition and interpersonal impairment in young adolescents with ADHD. Journal of Psychopathology and Behavior Assessment, 32, 193-202. doi:10.1007/s10862-009-9152-2

Journal of Attention Disorders, (June 9, 2015). DOI. This article is (C) SAGE Publications and permission has been granted for this version to appear in e-Publications@Marquette. SAGE Publications does not grant permission for this article to be further copied/distributed or hosted elsewhere without the express permission from SAGE Publications. 
NOT THE PUBLISHED VERSION; this is the author's final, peer-reviewed manuscript. The published version may be accessed by following the link in the citation at the bottom of the page.

Walker J. S., Coleman D., Lee J., Squire P. N., Friesen B. J. (2008). Children's stigmatization of childhood depression and ADHD: Magnitude and demographic variation in a national sample. Journal of the American Academy of Child and Adolescent Psychiatry, 47, 912920. doi:10.1097/CHI.0b013e318179961a

Wehmeier P. M., Schacht A., Barkley R. A. (2010). Social and emotional impairment in children and adolescents with ADHD and the impact on quality of life. Journal of Adolescent Health, 46, 209-217. doi:10.1016.j.jadohealth.2009.09.009

Wilens T. E., Biederman J., Brown S., Tanguay S., Monuteaux M. C., Blake C., Spencer T. J. (2002). Psychiatric comorbidity and functioning in clinically-referred preschool children and school-age youths with ADHD. Journal of the American Academy of Child \& Adolescent Psychiatry, 41, 262-268. doi:10.1097/00004583-200203000-00005 